\title{
Study on Evaluation of Carbon Accounting Information Quality in Coal-fired Power Generation Enterprises
}

\author{
Shaomei Yang ${ }^{1, a}$, Hong Du ${ }^{1, b}$, * \\ ${ }^{1}$ Department of Economics and Management, North China Electric Power University, NO.689 \\ Huadian Road, Baoding071003, China \\ a. yangshaomei77@126.com,b.630905654@qq.com \\ *Corresponding author
}

Keywords: Carbon accounting, Coal-fired power generation enterprises, Carbon accounting information quality, Content analysis.

Abstract: In this paper, by selecting the 2016 annual report or social responsibility report of China's five major coal-fired power generation groups and using content analysis method to make an empirical analysis of the carbon accounting information quality, we found that the carbon accounting information disclosure quality of the five major power generation groups is at medium level. The indicators with higher scores include Pollution Emission, Low-Carbon Awareness and Green Funding. The indicators with lower scores include Carbon Emission Investment, Carbon Emission Transaction. Then, we put forward a series of countermeasures to solve the problems of carbon accounting, including improving carbon accounting research system and guidelines, raising awareness of environmental protection, strengthening social supervision, increasing government carbon emissions monitoring, and implementing a carbon accounting auditing system.

\section{Introduction}

With the development of social economy and the deepening of people's understanding of the ecological environment, the change of ecological environment caused by greenhouse gas emission has been paid more and more attention. The low carbon economy has become a new economic development model pursued by various countries. In the low-carbon economy model, the carbon emission right is a new asset of enterprises and even the country, the concept of being incorporated into the accounting will have a deep connotation of the sustainable development of China's economy ${ }^{[1]}$. In recent years, the theory of carbon accounting is the emerging field of accounting academy in China; the state has not yet made a normative definition of carbon accounting, so the field has great potential for development ${ }^{[2]}$. Because the carbon accounting system is different from the traditional monetary accounting system, the carbon emissions will be quantified, which will 
enrich the accounting system ${ }^{[3]}$. In addition, carbon accounting theory is an important means to achieve green and low carbon economy in China. In accordance with the carbon accounting system to quantify the cost of carbon emissions, so that enterprises try to reduce carbon emissions and thus save costs. This will allow all economic organizations have low carbon emissions awareness and behavior, to promote the overall social low carbon green economic process. Carbon accounting is not only able to meet the information needs of stakeholders, but also to contribute to China's optimal allocation of resources and sustainable development.

However, due to China's low-carbon economy started late, most companies lack the motivation and awareness to disclose carbon accounting information. At present, there is no specific agency to carry out uniform provisions on the format or content of carbon emissions statements, therefore, different enterprises to disclose the relevant carbon accounting information format is not the same ${ }^{[4]}$. As high carbon emissions of coal-fired power generation enterprises should also have to bear the main responsibility for reducing greenhouse gas emissions. At the same time, "thermal power plant air pollutant discharge standards" in 2012 to implement, will achieve the task of low-carbon economy on the thermal power plant, and the "thirteenth Five" plan clearly requires large-scale power generation group in 2020, carbon dioxide emissions control In 550 grams of carbon dioxide / $\mathrm{kWh}$ or less, so the thermal power generation enterprises to become the focus of the development of low-carbon green economy transformation industry. Therefore, this article selected high-carbon emissions of five state-owned power plant in 2016 annual report or social responsibility report as a sample, with carbon accounting information disclosure as the object of study, the use of content analysis of its carbon accounting information quality evaluation.

\section{The status of carbon accounting}

Carbon accounting is based on low-carbon economic laws and regulations, under the guidance of sustainable development, the currency as the main unit, using a series of ways and means. We carry out continuous, systematic and comprehensive confirmation, measurement, recording and reporting on economic activities related to carbon emission reduction and carbon finance movement. To promote a specific body to fulfill the obligations of low-carbon and carbon emission reduction obligations, improve the utilization of natural resources and social benefits, the protection of the environment and the atmosphere of economic management activities ${ }^{[5]}$. Carbon Accounting This term is written by Stewart Jones in $2008^{[6]}$, commonly known as Carbon Emission and Sequential Accounting (CES), and the carbon accounting system is different from the traditional Accounting system that solves the problem of quantification of greenhouse gas emissions or biological interception, thereby forming a mechanism to limit greenhouse gas emissions. AnsKolk, David Levy and Jonatan Pinkse define the meaning of the two basic concepts of carbon accounting and carbon accounting information; describe the characteristics of its disclosure and the direction of the development of this problem. It does not object to the diversification of carbon accounting information disclosure at this stage because it can cover more information and will not be constrained by a standardized accounting system. In addition, the establishment and improvement of regulations and carbon emissions trading market will naturally regulate carbon accounting information disclosure, in turn, to promote the development of carbon accounting ${ }^{[7]}$.

Carbon accounting information is composed of accounting-based quantitative information and 
non-accounting-based qualitative information. Accounting-based quantitative information refers to the processing of carbon emissions information into billable and comparable financial information in accordance with the relevant regulatory regime. It can add the corresponding carbon accounting grade and secondary subjects to the original financial statements. In addition, carbon accounting statements can be prepared separately, such as carbon emission rights, carbon emissions measurement, R\&D investment ${ }^{[8]}$.

Qualitative carbon accounting information mainly includes the following five aspects:

(1). Corporate carbon emission policies and commitments, including environmental policies and objectives, environmental management system, enterprise environmental risks and countermeasures.

(2). Environmental governance, including the implementation and operation of environmental protection plan and the implementation of the results and the reasons for failure.

(3). Resource and energy consumption, including electricity, heat, coal and other resources, energy consumption and output ratio.

(4). Pollutant emission and comprehensive utilization, including waste water, waste gas and solid waste generation, emissions, comprehensive utilization and storage, and so on.

(5). Environmental quality and effect, including plant greening rate, the environmental impact of the communities and residents, environmental quality indicators and environmental quality management certification.

Carbon accounting information is not only monetary information, but also non-monetary information. With the country's emphasis on carbon emissions policies and the standardization of carbon emissions trading markets, information that can be measured in money is becoming richer, but there is no uniform specification, carbon accounting is fragmented, and disclosure is diversified.

\section{Construction of carbon accounting information quality evaluation system}

\subsection{Choose a method}

Through the inspection of the literature, it is concluded that the evaluation of accounting information quality mainly includes the authoritative method, the exponential analysis method and the content analysis method. At the international level, the authority rating method mainly has the transparency and information disclosure rating of the S \& $\mathrm{P}$ enterprise, the AIMR report and the CIFAR index. It has a very high authority, credibility and disclosure system norms, but the scope of application is limited; Exponential analysis is the use of index system, the number of quantitative analysis of the phenomenon of changes caused by the various factors affect the direction, extent and absolute quantity. It is highly viable, relatively more objective, but the workload is large. The content analysis method takes the relevant document information of the enterprise as the research object, and then obtains the method of overall evaluation by determining the score or value of each item. Content analysis can be qualitative literature into quantitative data, and then based on the data to make a quantitative analysis of the contents of the literature, and finally to the facts to judge and deduce.

China's securities market for the disclosure of carbon accounting information is not mandatory requirements, are voluntary disclosure; the government did not develop a rating system on the 
quality of carbon accounting information disclosure; there is no authority to measure the quality of carbon accounting information disclosure, It is appropriate for coal-fired power generation enterprises to use the content analysis method to measure the quality of carbon accounting information.

As a new research method, content analysis has the characteristics of systematic, objective and quantitative. The analysis steps are shown in Figure 1 below:

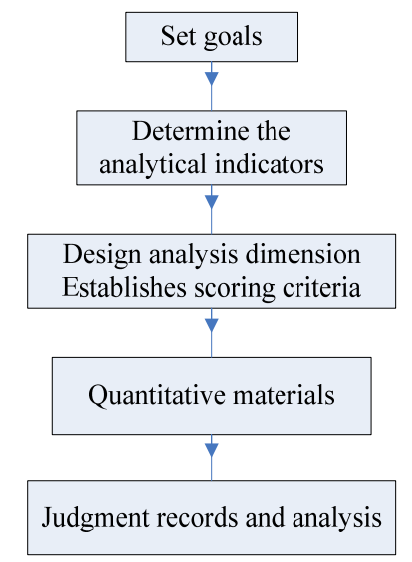

Figure 1 The steps of the content analysis

\subsection{Determine the scoring index}

According to "Thermal Power Plant Air Pollutant Discharge Standard", "Environmental Protection Law" and "Shanghai Stock Exchange listed company's environmental information disclosure guidelines". In this paper, the carbon accounting information quality evaluation index is divided into six items according to the above provisions and combined with the relevant information of the annual reports of the generating enterprises, namely: carbon emission investment, carbon emission fee, carbon emission transaction, environmental special subsidy, low carbon environmental awareness and pollution emission.

Carbon investment refers to the investment of coal-fired power generation enterprises to reduce carbon emissions, including the purchase and installation of environmental protection equipment, the construction of environmental protection projects and the corresponding staff wages; Carbon emissions costs refers to the sewage charges, the purchase of carbon emissions and green costs; carbon emissions trading refers to the company's carbon trading performance; Environmental protection special subsidy refers to the government by the funds, subsidies and tax relief and other preferential policies for enterprises to carry out environmental activities; Low-carbon awareness refers to the enterprise sets up the corresponding institutions, specific objectives and the corresponding plan for low-carbon management; Pollutant discharge refers to the type and discharge of pollutants arising from the production and operation activities.

\subsection{Scoring rules}

This paper draws on the scoring methods proposed by Darrell and Schwartz (1997), Freedman and Stagliano (1992) to rate the carbon accounting information quality of coal-fired power generation enterprises from three dimensions: significance, quantification and timeliness. 
(1). Significance(S), it is whether the carbon accounting information is disclosed in the annual report or in the social responsibility report. Significant Scoring Criteria: Carbon accounting information is not significant for the disclosure of the annual report and the social responsibility report, get 1 point; Only in the annual report or social responsibility report disclosed as significant, get 2 points; In addition to disclosure in the annual report and the social responsibility report, it is also disclosed by other means to be particularly significant, get 3 points.

(2). Quantification (Q), carbon accounting information disclosure is divided into quantitative information of monetary measurement and quantitative information of non-monetary quantification. Qualitative information was 1 point, quantitative information was 2 points, quantitative and qualitative information combined with 3 points.

(3). Timeliness ( $\mathrm{T}$ ), different time information has different value for information needs. Carbon accounting information can be divided into historical information, current information and future information. The future information was 1 point; the current information was 2 points; and compares the current information with the past information by 3 points. See Table 1 for details:

Table 1 Criteria for Quality Evaluation of Carbon Accounting Information 。

\begin{tabular}{|c|c|c|c|}
\hline Dimension & Judgment criteria & Scoring criteria & Score \\
\hline \multirow{3}{*}{$\mathrm{S}$} & \multirow{3}{*}{$\begin{array}{l}\text { Disclosure } \\
\text { location }\end{array}$} & Especially significant & 3 \\
\hline & & Significantly & 2 \\
\hline & & Not obvious & 1 \\
\hline \multirow{3}{*}{ Q } & \multirow{3}{*}{$\begin{array}{l}\text { Disclosure } \\
\text { method }\end{array}$} & Both quantitative and qualitative information & 3 \\
\hline & & Quantitative information & 2 \\
\hline & & Qualitative information & 1 \\
\hline \multirow[t]{3}{*}{$\mathrm{T}$} & \multirow[t]{3}{*}{ Disclosure time } & $\begin{array}{l}\text { Both present information and past } \\
\text { information }\end{array}$ & 3 \\
\hline & & current information & 2 \\
\hline & & future information & 1 \\
\hline
\end{tabular}

With the EID to represent the carbon accounting information quality evaluation score, the formula is as follows:

$$
E I D=\sum_{i=1}^{6}\left(S_{i}+Q_{i}+T_{i}\right) \quad(i=1,2, \cdots, 6)
$$

Where $S_{i}, Q_{i}, T_{i}$ represent the fraction of the i-th project of coal-fired power generation enterprises in terms of significance, quantification and timeliness, $S_{i}+Q_{i}+T_{i}$ indicating the total score of carbon accounting information on the i-th project. According to this method, it can be seen that the value area of the carbon quality information disclosure level is [0,54], and the value area of each content is $[0,9]$. 


\section{Empirical analysis}

This paper chooses China Huaneng Group, China Datang Corporation, China Guodian Corporation, China Huadian Corporation, and State Power Investment Corporation to conduct empirical analysis. The energy structure of the five power generation groups is shown in Table 2.

Table 2 Proportion of energy structure in five power generation enterprises

\begin{tabular}{|c|c|c|c|c|c|}
\hline & Huaneng & Datang & Guodian & Huadian & SPIC \\
\hline $\begin{array}{c}\text { Thermal } \\
\text { power }\end{array}$ & $76.5 \%$ & $68.05 \%$ & $66.83 \%$ & $71.45 \%$ & $61 \%$ \\
\hline Hydropower & $12.7 \%$ & $16.92 \%$ & $23.32 \%$ & $18.71 \%$ & $19 \%$ \\
\hline wind power & $9.9 \%$ & $10.01 \%$ & $9.42 \%$ & $8.84 \%$ & \\
\hline nuclear energy & & & & & $4 \%$ \\
\hline Solar energy & $0.9 \%$ & $0.66 \%$ & $0.43 \%$ & & $16 \%$ \\
\hline
\end{tabular}

From the above table, we can clearly see that in the energy structure of five power generation groups, the proportion of thermal power generation is the largest. Then according to the five power generation group of 2016 annual report and the social responsibility report, using the content analysis method to the empirical analysis of carbon accounting information quality, combined with the grading methods and calculation steps in the previous section, the score table are shown in table 3 below:

Table 3 Score of carbon accounting information quality

\begin{tabular}{|l|l|l|l|l|l|}
\hline & Huneng & Datang & Guodian & Huadian & SPIC \\
\hline Carbon Emission Investment & 7 & 2 & 2 & 2 & 6 \\
\hline Carbon Emission Fee & 7 & 7 & 7 & 0 & 0 \\
\hline Carbon Emission Transaction & 3 & 5 & 0 & 5 & 0 \\
\hline Green Funding & 7 & 7 & 7 & 7 & 5 \\
\hline Low-Carbon Awareness & 9 & 7 & 6 & 9 & 9 \\
\hline Pollution Emission & 9 & 9 & 9 & 9 & 9 \\
\hline Total & 42 & 37 & 31 & 32 & 29 \\
\hline
\end{tabular}

(1). Carbon Emission Investment is mainly scored based on whether investment in energy-saving and environmental protection is displayed in the annual report or social responsibility report. Only China Huaneng Group and State Power Investment Corporation show total investment in environmental protection and other three companies did not carry out an accurate and comprehensive description, but by virtue of the subjective description of a qualitative, less posteriori.

(2). Carbon Emission Fee is scored according to the subject of sewage charges or environmental protection fee paid in other cash-related items related to operating activities in the annual report. Since there is no explicit stipulation in relevant laws and regulations, China Huadian Corporation and State Power Investment Corporation failure to set this subject resulting in a lower comparable.

(3). Carbon Emission Transaction is mainly based on the annual report or social responsibility 
report on the carbon asset transactions to score, none of them have conducted a quantitative disclosure of their carbon asset transactions, just participating in the nationwide carbon market by issuing some carbon deals.

(4). Green Funding is mainly based on Government Grants Detail Subjects in the Non-operating Income Subjects to score. China Huaneng Group, China Datang Corporation and China Huadian Corporation set up Environmental Subsidy Details Subject; China Guodian Corporation set up Environmental Special Fund Details Subject, Only State China Power Investment Corporation did not set a detailed account of Government Grants Detail Subjects. From which we can see the details of the subjects set chaos, there is no clear rule.

(5). Low carbon awareness is based on the power generation enterprises to develop circular economy and the promotion of low-carbon office to score. The five power generation groups always adhere to the concept of low-carbon, making this concept popular among people, so the score is higher.

(6). Pollution Emission is mainly based on the emission performance of sulfur dioxide, nitrogen oxides, soot and exhaust gas. Due to the explicit stipulations of laws and regulations, each power plant pollution emission indicator must be fully disclosed, so the overall score is the highest.

From the above conclusions, we can see that the carbon accounting information disclosure quality of the five major power generation groups is at medium level. The indicators with higher scores include Pollution Emission, Low-Carbon Awareness and Green Funding. The indicators with lower scores include Carbon Emission Investment, Carbon Emission Transaction.

In addition, China does not have laws and regulations related to the disclosure of carbon accounting information. All power generation companies implement the principle of voluntary disclosure of carbon accounting information. It can be seen from the annual report or social responsibility report of the power plant released time that the carbon accounting information disclosure is not timely. Because there is no explicit law and regulation to stipulate the time, the power generation enterprises will not disclose in time, which will make carbon accounting information demanders unable to obtain timely information on time-sensitive environmental protection events. In general, the disclosure of carbon accounting information of power generation enterprises is very random, lack of continuity, and the chaos of carbon accounting information disclosure model and content leads to the users being unable to conduct horizontal and vertical comparison among power generation enterprises. Nor can we calculate the financial impact of environmental protection activities.

\section{Conclusion}

Based on the above evaluation of carbon accounting information quality for power generation enterprises, the following improvements are suggested:

(1). Improve the carbon accounting research system and guidelines. The current "Accounting Law" and "Accounting Standards for Business Enterprises" does not include the content of carbon accounting in China, and the development of low-carbon economy cannot be separated from a sound carbon accounting system. First of all, it is very necessary for the departments concerned to make mandatory disclosure of carbon accounting. Regulating the carbon accounting 
information disclosure model can be disclosed in the social responsibility report, or the carbon accounting report can be prepared separately. Second, we must standardize the carbon accounting information disclosure content of power generation enterprises to ensure the authenticity, accuracy and completeness of carbon accounting information. Third, it is also important to develop a uniform accounting and measurement methodology for carbon emission investment, carbon emission fee and carbon emission transaction. Finally, it is necessary to establish a comprehensive and accurate carbon accounting performance evaluation system, which is conducive to the effective combination of the environment and enterprises, promoting the realization of corporate environmental goals.

(2). Raise environmental awareness and strengthen social supervision. As one of the main sources of carbon emissions, power generation enterprises should take more cost of natural environment governance and take the initiative to disclose carbon accounting information. At this moment, managers and financial personnel who are closely related to disclosure of carbon accounting information should improve their own environmental awareness and reserve of environmental knowledge to promote low-carbon awareness so that every employee voluntarily assume the responsibility of energy conservation and emission reduction.

(3). The government should step up its efforts to monitor carbon emissions and implement a carbon accounting auditing system. First of all, the government can increase the environmental pollution penalties and supervision of power generation enterprises, when the penalty cost is greater than or equal to the purchase cost of environmental protection equipment, enterprises will choose to purchase environmental protection equipment in the hope of bringing long-term economic benefits, so as to realize the development of a low-carbon economy. Second, the government may consider formulating relevant carbon accounting laws and setting up a special inspection agency to achieve a low-carbon economy. Finally, in order to improve the level and quality of corporate carbon accounting information disclosure in the background of low-carbon economy, it is necessary to establish auditing system of carbon accounting information and provide legal basis. Under the guidance of the environmental auditing system, the government and non-government formal auditing organizations should be established and the carbon accounting auditing activities should be actively carried out so as to finally achieve the sustainable development of social economy.

By evaluating the carbon accounting information quality of power generation enterprises, we found the existing problems of carbon accounting information disclosure in power generation enterprises and put forward a series of countermeasures. It also provides some references for other carbon emission enterprises and improves our accounting system. In addition, there are some shortcomings in this paper, the sample selected is small and the evaluation method is simple, and needs further improvement.

\section{Acknowledgements}

This work was supported by the Fundamental Research Funds for the Central Universities (NO.2016MS126). 


\section{References}

[1]. Zhang Caiping, Xiao Xu. The Present Situation of International Carbon Disclosure and Its Enlightenment to China (J). Finance and Finance, 2010, (3): 77-80.

[2]. Song Yayun. Carbon accounting development status and thinking [J]. Guangdong Economy, 2017, (8): 128.

[3]. Xiao Xun, Zheng Ling. Study on the Construction of Enterprise Carbon Accounting System under Low-carbon Economy [J]. China Population Resources and Environment, 2011,21 (8): 55-60

[4]. Dutta S, Lawscn R. Value Chain Analysis for Environmental Factors [J] . Cost Management, 2008, (3-4): 5-14.

[5]. Chang Si. Study on the Relationship between Carbon Accounting Information Disclosure Quality and Equity Cost of Electric Power Enterprises [D] .Changsha University of Science and Technology, 2015.

[6]. Jan Bebbington et al. Carbon Trading: Accounting and Reporting Issues [J].European Accounting Review, 2008(04) : 10-18

[7]. Ans Kolk, David Levy, Jonatan Pinkse. Corporate Responses in an Emerging Climate Regime: The Institutionalization and Commensuration of Carbon Disclosure [J]. European Accounting Review, 2008, 17(4): 719-745

[8]. Guo Yanxia. Study on Environmental Accounting Information Disclosure of China's Iron and Steel Enterprises under the Background of Low Carbon Economy [D] .Anhui University, 2015. 